
\title{
ROLE OF MODELLING IN CONTROL OF ASTHMA IN CHILDREN
}

Received 3 May 2020;

Received in revised form 5 June 2020;

Accepted 12 June 2020

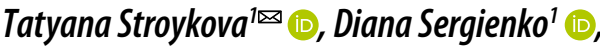 Olga Bashkina ${ }^{1} \mathbb{D}^{0}$, Yury Mizernitskiy ${ }^{2}$ (D) Dmitriy Leshchev ${ }^{3}$}

\section{${ }^{1}$ Astrakhan State Medical University, Astrakhan; \\ ${ }^{2}$ Research and Clinical Institute for Pediatrics at Pirogov Russian National Research Medical University, Moscow; \\ ${ }^{3}$ Center for Advanced Studies, Peter the Great St. Petersburg Polytechnic University, St. Petersburga}

\section{mega.astor@mail.ru}

ABSTRACT — The study included 172 children of both sexes, aged 3 to 17 years with atopic bronchial asthma. The influence of various factors on the level of asthma control was analyzed by using a regression model. The following parameters were analysed: duration of disease, FEV1, IgE level, age. The best constructed logistic regression model revealed a sensitivity of 73.8 and specificity of 71.2. Distribution analysis and modelling confirmed that the regression model has a limited application for the construction of asthma control models due to nonlinear effects.

KEY W ORDS — asthma, FEV1, IgE, children, regression model, control.

\section{B A C K GRO UN D}

The problem of asthma control is multifaceted and difficult to solve despite being well studied. Modern advances in pharmacotherapy and monitoring of asthma still do not completely help in controlling the disease. The assessment can be carried out after several months of controller treatment and if possible after an attempt to reduce intensity of treatment in order to determine its minimum effective level for each patient. Since the course of asthma is extremely variable, severity of the disease can vary over months and years $[1,2,3,4]$.

Unfavorable prognosis in terms of development of bronchial asthma in patients with obstructive bronchitis is indicated by the following signs: family history of allergy, patients with chronic infection-allergic diseases, complication of pregnancy, artificial feeding from the first days of life, increased IgE. [5, 6].

\section{MATERIALS AND METHODS}

The study comprised of 172 children of both sexes with atopic bronchial asthma. The severity of the disease was different. In all examined children, the diagnosis of the disease was determined and verified on the basis of diagnostic criteria and the current classification of the disease in accordance with the provisions of the National Program Asthma in Children. Treatment strategy and prevention, Moscow, revised 2017 [1].

First of all, the statistical interaction of each factor with the control level (three-level / two-level) was separately examined using the criterion $\chi^{2}$ and the Fischer's Exact Test for both qualitative and categoric measurement, and with the Mann-Whitney Test criterion (Wilcoxon Rank Sum Test With Continuity Correction) for the continuous variables. The criterion values and $\mathrm{p}$-value are shown in Chart 1 .

The effect of various factors on the level of asthma control was analysed using regression model. The following parameters were included in the analysis: duration of disease, FEV1, level of $\operatorname{IgE}$, age.

The sequential selection method was used to build the logistic regression model adjusted for all factors.

All obtained coefficients and model parameters are shown in Table 1 . The P-value for the model coefficients was calculated by the Wald test.

The probability of asthma control can be calculated using the formulas:

$$
Y=a_{1} \cdot x_{1}+a_{2} \cdot x_{2}+\cdots+a_{n} \cdot x_{n}+a_{0}
$$

$\mathrm{P}=\frac{1}{1+e^{-Y}} \operatorname{logistic}$ function.

where $a_{i}$ is the coefficients for the corresponding values of the factors $x_{i}, a_{0}$ is a constant term, $e$ is the base of the natural logarithm.

\section{RESULTS AND DISCUSSION}

The analysis of clinical and anamnestic parameters and their influence on disease control was carried out.

According to the data in Table 1 asthma severity plays a key role in achieving control of the disease. Age and FEV1 (in model 1) have insignificant coefficients; these factors have a non-linear nature of the relationship with the control factor.

The disease duration coefficient is positive, which means that the longer the duration is, the more often disease control is achieved. The total IgE level, conversely, has a negative coefficient: the larger it is, the less likely it is to control the disease. 
Table 1. Interaction between the factors and the control over bronchial asthma

\begin{tabular}{|c|c|}
\hline Factor & $\begin{array}{l}\text { Criterion value and p-value for two-level and three-level control } \\
\text { classification }\end{array}$ \\
\hline Sex & $\begin{array}{l}\chi^{2}=0,35, p \text {-value }=0,84 \\
\chi^{2}=0,185, p \text {-value }=0,67\end{array}$ \\
\hline Age $^{*}$ & $\begin{array}{l}0-1: W=1638, p \text {-value }=0,35 \\
0-2: W=1132, p \text {-value }=0,12 \\
1-2: W=1445, p \text {-value }=0,006 \\
W=2577, p \text {-value }=0,009\end{array}$ \\
\hline BA severity & $\begin{array}{l}\text { Fisher's Exact Test, } \mathrm{p} \text {-value }=1,4 \mathrm{e}-05 \\
\chi^{2}=24,017, \mathrm{p} \text {-value }=6,0 \mathrm{e}-06\end{array}$ \\
\hline Onset age* & $\begin{array}{l}0-1: W=1604,5, p \text {-value }=0,47 \\
0-2: W=1561, p \text {-value }=0,22 \\
1-2: W=2125,5, p \text {-value }=0,58 \\
W=3686,5, p \text {-value }=0,33\end{array}$ \\
\hline $\begin{array}{l}\text { Genetic back- } \\
\text { ground }\end{array}$ & $\begin{array}{l}\chi^{2}=0,82843, p \text {-value }=0,66 \\
\chi^{2}=0,14649, p \text {-value }=0,7\end{array}$ \\
\hline Illness duration* & $\begin{array}{l}0-1: W=1381, p \text {-value }=0,53 \\
0-2: W=929,5, p \text {-value }=0,0045 \\
1-2: W=1456, p \text {-value }=0,007 \\
W=2385,5, p \text {-value }=0,0013\end{array}$ \\
\hline
\end{tabular}

Table 2. Value of the coefficients of logistic regression and parameters of models

\begin{tabular}{l|l|l|l}
\hline Factors*/Parameters & Model 1 & Model 2 & Model 3 \\
\hline Disease duration & $0.18746(0.01)$ & $0.18355(0.0002)$ & $0.13633(0.0013)$ \\
\hline Asthma severity & $-1.54523(4.9 \mathrm{E}-06)$ & $-1.62231(1.0 \mathrm{E}-06)$ & - \\
\hline Total lgE & $-0.00236(0.044)$ & $-0.00236(0.04)$ & - \\
\hline Age & $-0.004(0.96)$ & - & - \\
\hline FEV & $0.02208(0.8)$ & - & $0.03047(0.0097)$ \\
\hline Constant term & 0.60668 & 2.3427 & -3.62426 \\
\hline$\chi^{2}$ & 48.195 & 44.960 & 17.566 \\
\hline p-value & $3.2 \mathrm{E}-09$ & $9.4 \mathrm{E}-10$ & 0.00015 \\
\hline $\mathrm{R}^{2}$ & 0.215 & 0.201 & 0.079 \\
\hline Sensitivity & 72.9 & 73.8 & 65.6 \\
\hline Specificity & 75.4 & 71.2 & 65.8
\end{tabular}

Thus, we suggested that in this system of factors there are nonlinear relationships which were confirmed by further modelling. In particular, the decision tree model was also built based on these factors which had sensitivity of 92.79 and specificity of 81.96 .

\section{CONCLUSION}

The best model of the constructed logistic regression models gives specificity of 71.2 and sensitivity of 73.8. Distribution analysis and modelling show the limited application of the regression for the construction of asthma control models due to the nonlinear effects.

Thus, the modelling method allows to evaluate the role of various factors and their effect on the course of the disease and to predict the control effectiveness.
Elaboration of predictive markers for development of bronchial asthma in children will help improve the effectiveness of its diagnosis; timely initiation of preventive and therapeutic measures, which, in due course, may prevent disability in this group of patients.

\section{REFERENCES}

1. National Program "Asthma in Children. Treatment strategy and prevention", Moscow, revised 2017. 159 p.

2. Federal clinical guidelines for the diagnosis and treatment of asthma. Russian Respiratory Society. 2013. http://minzdrav. gov-murman.ru/documents/poryadkiokazaniya-meditsinskoy-pomoshchi/ clinasthma22013(3).pdf/ F

3. Chuchalin A.G., Khaltaev N., Antonov N. Chronic respiratory diseases and risk factors in 12 regions of the Russian Federation // International Journal of COPD 2014:9 963-974

4. GLObal INitiative for Asthma (GINA). Pocket Guide for Asthma Management and Prevention in Children 5 Years and Younger, updated April 2015. Available from: http://www.ginasthma. org/local/uploads/files/GINA_PediatricPocket_2015.pdf

5. Rosenberg H, Druey K. J Leukoc Biol 2018 Jul;104(1):41-48. doi: 10.1002/ JLB.3MR1117-436R

6. Khodzhaeva I, Karimova M. Forecasting of risk of the development of bronchial asthma in patients with obstructive bronchitis / / Young Scientist. 2016. — \#11 (115). - pages 1182-1184.

7. Seliverstova E., Gaparkhoeva Z, Bashkina O, STroikova T, Averina I. Clinical Immunologic Monitoring and Prognostication of the relapsing course of obstructive bronchitis in children // Digest of the $3^{\text {rd }}$ Russian Congress "Molecular foundations of clinical medicine - potential and realistic", S.Petersburg 2015. - pages 132-134. 